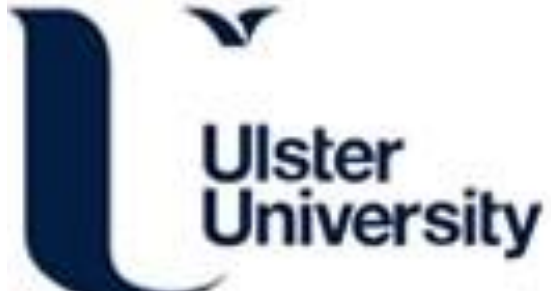

Knowledge coordination via digital artefacts in highly dispersed teams

Fang, Y., Neufeld, D., \& Zhang, X. (2021). Knowledge coordination via digital artefacts in highly dispersed teams. Information Systems Journal. https://doi.org/10.1111/isj.12358

Link to publication record in Ulster University Research Portal

\section{Published in:}

Information Systems Journal

Publication Status:

Published online: 13/08/2021

DOI:

10.1111/isj. 12358

\section{Document Version}

Author Accepted version

\section{General rights}

Copyright for the publications made accessible via Ulster University's Research Portal is retained by the author(s) and / or other copyright owners and it is a condition of accessing these publications that users recognise and abide by the legal requirements associated with these rights.

\section{Take down policy}

The Research Portal is Ulster University's institutional repository that provides access to Ulster's research outputs. Every effort has been made to ensure that content in the Research Portal does not infringe any person's rights, or applicable UK laws. If you discover content in the Research Portal that you believe breaches copyright or violates any law, please contact pure-support@ulster.ac.uk. 


\title{
Knowledge Coordination via Digital Artifacts in Highly Dispersed Teams
}

\author{
Yulin Fang, City University of Hong Kong \\ Derrick Neufeld, Ivey Business School, Western University \\ Xiaojie Zhang, China Ocean University
}

\begin{abstract}
Virtual teams face the unique challenge of coordinating their knowledge work across time, space and people. Information technologies, and digital artifacts in particular, are essential to supporting coordination in highly dispersed teams, yet the extant literature is limited in explaining how such teams produce and reproduce digital artifacts for coordination. This paper describes a qualitative case study that examined the day-to-day practices of two highly dispersed virtual teams, with the initial conceptual lens informed by Carlile's (2004) knowledge management framework. Our observations suggest that knowledge coordination in these highly dispersed virtual teams involves the continuous production and reproduction of digital artifacts (which we refer to as technology practices) through three paired modes: “presenting-accessing” (related to knowledge transfer); "representing-adding" (related to knowledge translation); and "molding-challenging" (related to knowledge transformation). We also observed an unexpected fourth pair of technology practices, "withholding-ignoring", that had the effect of delaying certain knowledge coordination processes. Our findings contribute to both the knowledge coordination literature and the practical use of digital artifacts in virtual teams. Future research directions are discussed.
\end{abstract}

Keywords: virtual teams, knowledge coordination, digital artifacts, boundary objects, knowledge management, qualitative study 


\section{Introduction}

Geographically dispersed 'virtual' teams have become commonplace in organizations, performing mission-critical tasks (Magni et al., 2018; Gilson et al., 2015; Raghuram et al., 2019), with renewed importance apparent during the worldwide COVID-19 pandemic (Kilcullen et al., 2021; Waizenegger et al., 2020). Coordinating and managing knowledge across spatial, temporal, and organizational boundaries has been a persistent challenge for virtual teams (e.g., Kotlarsky et al., 2014), as evidenced by the "out of sight, out of sync" problem (Hinds \& Bailey, 2003; O'Leary et al., 2014), as well as difficulties in achieving shared understanding among organizational members due to lack of a common work context (Cramton, 2001). An array of research has appeared to explore and address virtual team knowledge coordination challenges and gaps (e.g., Brotheridge et al., 2015; Kudaravalli et al., 2017; Mehta \& Bharadwaj, 2015; Mesmer-Magnus et al., 2011; Romanow et al., 2018; Zimmermann \& Ravishankar, 2014), and yet mysteries persist.

As dispersed team members rely heavily, often exclusively, on information technologies (IT) to coordinate their work, the use of IT as a tool has been a common focal point for understanding how knowledge is managed across boundaries (Iyengar et al., 2015; Leonardi \& Bailey, 2017; O'Leary et al., 2014). Much prior virtual team research has made IT tools the foci of investigation (e.g., Alavi \& Tiwana, 2002; Choi et al., 2010; Iyengar et al., 2015; Qureshi et al., 2018; Reid et al., 2016; Tim et al., 2017). Yet limited scholarly attention has been paid to the role of digital artifacts, namely entities that are generated through the use of the IT tools (Ekbia, 2009; Faulkner \& Runde, 2019; Kallinikos et al., 2013), in the virtual team context. Indeed, digital artifacts (e.g., email messages, documents, work assignments) are quite distinct from the IT tools used to produce them (e.g., email systems, productivity software, cloudbased systems). In this study, we are interested in examining how digital artifacts, rather than IT tools, are used as vehicles to iteratively communicate, negotiate, and coordinate knowledge among virtual team members (Ekbia, 2009; Arazy et al., 2020). Thus, we set out to address the research question: How do members in highly dispersed teams utilize digital artifacts to coordinate their knowledge work?

To address this question, the present study identifies technology practices, defined as ways through which team members produce and reproduce digital artifacts, by extending Carlile's (2004) knowledge management framework to the virtual team context. Carlile (2004) identified three knowledge coordination processes, namely transfer, translation, and transformation, and discussed how these processes function to overcome different types of knowledge boundaries via physical boundary objects in a collocated setting. Extending Carlile's framework to the virtual team context, and by using in-depth case studies to analyze two virtual teams, we identify four pairs of technology practices related to digital artifacts that virtual team members routinely use to coordinate their knowledge work. 
The current study contributes to the literature in several ways. First, it adds to the growing body of literature on knowledge coordination in virtual teams by identifying technology practices that utilize digital artifacts as a central coordinating mechanism. The analysis of technology practices related to digital artifacts provides an additional perspective for understanding the role of IT artifacts in knowledge coordination in virtual teams, and responds to the call for a closer examination of IT artifacts as the 'core' in the IS field (Faulkner \& Runde 2019). Second, prior literature has considered boundary objects as being either technological artifacts with predetermined properties, or technologies dichotomized as use versus non-use (e.g., Barrett \& Oborn, 2010; Levina \& Vaast 2005). We contribute to this boundary object literature by identifying four pairs of technology practices related to the production and reproduction of digital artifacts, thereby extending the understanding of how digital artifacts function as boundary objects "in the making", beyond the dichotomy of use versus non-use of boundary objects. In addition, this study contributes to Carlile's (2004) knowledge management framework by extending its application from the collocated team context to that of highly distributed teams. Finally, our study reveals two additional practices, withholding and ignoring, that routinely occur in the distributed work setting. In contrast to previous studies that have exclusively emphasized the negative effects of such activities, we offer a discussion around the potentially beneficial aspects that these activities may play in knowledge coordination, particularly in the virtual team context where members rely heavily or exclusively on digital artifacts.

\section{Literature Review - Knowledge Coordination in Virtual Teams}

Coordinating knowledge among team members is a critical capability of high-performing project teams (Tiwana \& Mclean, 2005; O'Leary et al., 2014). The concept of work coordination is traditionally defined as the management of interdependencies among task activities (Malone \& Crowston, 1994). Whereas low-level, individual, routine tasks can be effectively coordinated through standardization of formal rules and routines, the same cannot be said for high-level, interactive, complex tasks that demand more sophisticated coordination mechanisms, and this is where knowledge coordination plays a critical role (Grant, 1996). In this study, knowledge coordination is defined as the management of knowledge interdependencies across boundaries (Kudaravalli et al., 2017), including processes such as sharing and using individually held knowledge for the purpose of accomplishing complex collective tasks.

Our context for understanding complex, interdependent knowledge coordination is the highly dispersed virtual team, defined as a functioning work group that relies on IT-mediated and asynchronous communication tools to span large geographic and temporal boundaries (Martins et al., 2004; Gilson et al., 2015). Virtual teams face challenges from geographic dispersion that prevents regular face-to-face meetings, and temporal boundaries (e.g., time zones differences) that make synchronous communication 
difficult and task coordination unreliable (O'Leary \& Cummings, 2007). Virtual teams attempt to "sidestep" these constraints by using a broad repertoire of information and communication technologies (ICTs) to accomplish their work (Kilcullen et al., 2021; Gilson et al., 2015; Watson-Manheim \& Bélanger, 2007). In the process, team members create and rely on digital work artifacts, which become instrumental to coordinating the team's collective knowledge work.

Research on distributed work has identified three general approaches that enable knowledge coordination in virtual teams: technological, cognitive, and social mechanisms. The technological perspective focuses on the roles or features of IT in dispersed work contexts related to building mutual knowledge (Cramton, 2001), shortening perceived distance (O'Leary et al., 2014), and sharing information and knowledge (Mesmer-Magnus et al., 2011). For example, Mesmer-Magnus et al. (2011) conducted a meta-analysis and found that teams with virtual communication tools of moderate synchronicity engaged in more information sharing activities. The second mechanism, shared cognitive models, are used to achieve coordination consistent with Kanawattanachai and Yoo's (2007) transactive memory systems (TMS) theory, in which ICT-based task-orientated communications lead to improvements in knowledge specification and reliability, knowledge coordination, and team performance. Likewise, distributed work studies have examined how socio-cognitive sensemaking activities influence the co-creation of congruent understandings (Vlaar et al., 2008), and how shared team knowledge can affect task coordination (Espinosa et al., 2007). A third general mechanism, social processes, is also instrumental to enabling knowledge coordination in virtual teams. For example, social capital (Robert et al., 2008) and trust (Peñarroja et al., 2013) have been closely associated with coordination in distributed teams. Additional studies have verified the effects of trust and commitment of distributed members on knowledge sharing (Golden \& Raghuram, 2010), and of relational strength on task coordination (Tzabbar \& Vestal, 2015).

Although these studies have identified many important factors associated with coordination in general and knowledge coordination in particular, few studies have examined digital artifacts that virtual teams routinely produced to coordinate their teamwork. In this paper we differentiate digital artifacts from IT tools, as discussed in several recent theoretical works on IT artifacts (Faulkner \& Runde, 2019; Kallinikos et al., 2013; Slavova \& Karanasios, 2018). For example, an email system is an IT tool, whereas an email message is a digital artifact. The language used to describe these concepts is interesting; whereas IT tools are 'used' and 'leveraged', digital artifacts are 'produced' and 'reproduced'. Digital artifacts are provisional products or outputs of teamwork, produced with the help of information and communication technology, and reliant on continuous inputs, adaptations, and applications by contributors as the team responds to specific and well-defined tasks, as well as unpredictable and evolving 
environments (Arazy et al., 2020). Thus, digital artifacts are considered to be continuously 'in progress' or 'in the making' (Kallinikos et al., 2013). In contrast to traditional teams that can easily engage in collocated and synchronous interaction, highly dispersed teams rely heavily or exclusively on digital artifacts for coordinating their work.

Despite the variety, volume, and pervasiveness of digital artifacts, we know little about how virtual team members coordinate their knowledge through the production and reproduction of digital artifacts. One notable exception is Levina (2005) who examined IS development team processes by looking at their digital artifacts; however, this study did not look specifically at knowledge coordination processes. As digital artifacts rely on knowledge inputs from members, they become the repository of the team's explicit and tacit knowledge (Arazy et al., 2020). Thus, digital artifacts, and the practices surrounding their production and reproduction, which we term as technology practices, play an essential role in coordinating knowledge across boundaries in virtual teams.

Understanding how technology practices are used to coordinate virtual team knowledge, i.e., how digital artifacts are produced and reproduced, requires deeper examination on the concept of knowledge coordination. There is a tendency to treat the process of coordinating knowledge categorically, as knowledge transfer (e.g., Iyengar et al., 2015), knowledge sharing (e.g., Alsharo et al., 2017), or just knowledge coordination (e.g., Kanawattanachai et al., 2007; Kotlarsky et al., 2014). However, we argue that knowledge coordination is a multi-faceted and complex phenomenon that requires nuanced treatment. When individuals attempt to coordinate their knowledge with one another, they must overcome different levels of knowledge boundaries that exist between them (Carlile, 2004; Kotlarsky et al., 2014). For example, knowledge sharing will be blocked if people don't speak the same language; the language boundary must be spanned before knowledge can be shared and coordinated. The next section provides insights to different knowledge boundaries by reviewing Carlile's (2004) knowledge management framework.

\section{Managing Knowledge Boundaries Using Boundary Objects}

\subsection{Knowledge Boundaries}

Informed by the communication theory work of Shannon and Weaver (1949), Carlile (2004) conceptualized three knowledge boundaries that exist in traditional (collocated) product development teams: syntactic, semantic, and pragmatic. Because knowledge coordination requires managing knowledge across different domains (Deng et al., 2015; Kotlarsky et al., 2014), Carlile's framework distinguished three knowledge coordination processes - knowledge transfer, knowledge translation, and knowledge transformation - and discussed how each process spans different types of knowledge boundaries through the use of physical boundary objects. Carlile's (2004) framework provides an 
excellent theoretical base to build a deeper understanding of the role of digital artifacts in virtual team knowledge coordination, because it explicitly acknowledges that boundary objects play a central role.

Syntactic knowledge boundaries appear when team members do not have a shared or stable syntax (vocabulary), or when novel syntax is introduced (Carlile, 2004). For example, a group of individuals who share a common professional or experiential background often develop a shared repertoire of words, stories, symbols, genres, codes, and abbreviations (Wenger, 1998). Knowledge held by this group will naturally be localized around and embedded in their shared repertoire, even if the syntax is unfamiliar and indecipherable to outsiders. In one study investigating a community of insurance processors, Wenger (1998) reported that the employees had condensed a complex set of insurance terms down into short, cryptic phrases that were not meaningful to anyone outside of the community. In order to span syntactic boundaries and engage in knowledge transfer, team members adopt a shared syntax. This is consistent with the organizational informatioan processing perspective, which narrows the problem of transfer to one of "matching differences" through a shared syntax across the boundary (Lawrence \& Lorsch, 1967). It also meets Galbraight's (1973) requirement of establishing "adequate information processing capacity" for organizing complex activities. In effect, when a common repertoire has been established, knowledge has the potential to flow unimpeded across boundaries.

Semantic knowledge boundaries occur when team members are unable to share knowledge because they have different interpretations about "what it means" (Carlile, 2004). Interpretation differences can arise when individuals adopt disparate cognitive maps resulting from variations in personal experience, background and skill, or when they occupy different "thought worlds" (Dougherty, 1992). Between members in a community of practice, for example, individuals may derive disparate meanings based on local ways of doing things (Brown \& Duguid, 2001), even if they share a common syntactical lexicon of symbols, graphs or words. In Zuzul's (2019) study of collaboration in the design of two smart cities, concept ambiguity ("What is a smart city?") revealed that semantic, and likely also syntactic, boundaries were operating. Spanning semantic boundaries, a process Carlile (2004) called "knowledge translation", focuses on first learning about the sources that led to interpretive differences, and then developing a common understanding using objects such as standardized forms and methods. Semantic boundaries can be spanned by paying attention to the challenges of conveyed meaning and different interpretations (Nonaka \& Takeuchi, 1995), engaging in mutual interaction (Nonaka, 1994), or building communities of practice (Brown \& Duguid, 2001). Nonaka (1994) suggested that the semantic aspect is most relevant to knowledge creation and innovation, as the word semantic literally means "new meaning".

Pragmatic knowledge boundaries occur when the flow of knowledge between team members is constrained by diverse individual interests - in other words, differences in "why it matters" to each 
individual (Brown \& Duguid, 2001; Carlile, 2004; Carlile, 2002). A pragmatic knowledge boundary can arise when knowledge from one division of practice causes potentially unfavorable consequences for another (Carlile, 2002). Knowledge is consequential to practice because, by definition, it relates to the capacity to enhance effective action, and is action-oriented by nature (Wenger, 1998). Knowledge reflects significant investment of the knowledge holder's previous efforts and commitments (Nonaka, 1994).

When knowledge favorable to one individual or group is unfavorable to another, reconciliation is required before effective and pragmatic knowledge coordination can occur. In Zuzul's (2019) study on smart city collaboration, process ambiguity ("How do we build a smart city?") was a pragmatic boundary. Approaches to spanning pragmatic knowledge boundaries, which Carlile (2004) termed "knowledge transformation", entails revisiting and altering existing knowledge stores and developing new collective knowledge elements. Such processes require a willingness to compromise existing community practices, interests, and values, and making significant investments in building relationships (Carlile, 2002; Levina, 2005). Ultimately these are high-risk activities, because they may result in favorable or unfavorable consequences for the individual (Carlile, 2002, 2004).

This framework was originally theorized and validated in the traditional (collocated) team context, wherein knowledge boundary spanning involves direct interpersonal exchange. However, direct interaction is impossible in highly dispersed teams due to geographical, temporal, and organizational dispersion. Knowledge boundary spanning in highly dispersed teams must rely heavily, perhaps even exclusively, on the production and reproduction of digital artifacts. As such, while Carlile's (2004) framework offers an excellent conceptual foundation for exploring a more nuanced understanding of knowledge coordination through the different processes of spanning knowledge boundaries, it must be adapted to the virtual team context by carefully addressing the indispensable, rather than supplementary, role of digital artifacts. We posit that the role of digital artifacts can be appreciated through the conceptual lens of boundary objects (Kallinikos et al., 2013).

\subsection{Digital Artifacts as Boundary Objects}

Boundary objects are defined as manufactured artifacts that span boundaries by establishing a shared perspective that "sits in the middle" (Carlile, 2002; Star, 1989), thus helping manage interconnections (Wenger, 1998). The term refers to a broad range of artifacts that "are plastic enough to adapt to local needs and constraints of the several parties employing them, yet robust enough to maintain a common identity across sites" (Star, 1989, p. 393). Examples include physical product prototypes, design drawings, standardized reporting forms, and various types of IT-related tools such as document archives, enterprise resource planning systems, and social media (Bechky, 2003; Boland Jr et al., 2007; Leonardi et al., 2019; Tim et al., 2017). Because boundary objects comprise team members' individual and collective 
practices, and in turn can actively influence those practices, boundary objects become "writing and rewriting devices" - tools used to objectify and negotiate services or work demands, which can make otherwise highly complex collective actions manageable and controllable (Callon, 2002).

Previous studies on boundary objects fall into two main streams: (1) properties that boundary objects are supposed to have; and (2) dichotomized in-use versus non-use of boundary objects (e.g., Barrett \& Oborn, 2010; Levina \& Vaast 2005). Properties that have been associated with effective boundary objects include modularity, abstraction, accommodation, standardization, tangibility, accessibility, timeliness, and concreteness (Huvila et al., 2017; Leonardi et al., 2019; Star, 1989; Bechky, 2003). These properties have been further associated with particular types of boundary objects. For instance, application databases and knowledge repositories usually share a common syntax to afford easy transference, whereas objects, models, and maps support the transformation of knowledge from one form to another (Carlile, 2002). 'Inuse' boundary objects (i.e., objects that people significantly interact with and through which they develop a shared identity) can be highly effective, whereas those that are not used (i.e., merely 'designated', neglected, or only superficially used) may be ineffective for knowledge sharing (Huvila et al., 2017; Levina \& Vaast, 2005; Jarzabkowski \& Kaplan, 2014).

In contrast to these two streams, this study focuses on technology practices, i.e., the production and reproduction practices of digital artifacts, as one particular, essential, yet understudied aspect of boundary object. Digital artifacts are "quasi-objects" (Ekbia, 2009) that are intentionally incomplete, and continuously 'in the making' (Kallinikos et al., 2013). Digital artifacts may be constantly updated, modified, accessed by other digital artifacts, transmitted through various sources, and subject to modification by actors of underlying logic (Arazy et al., 2019; Kallinikos et al., 2013). It is these characteristics that enable digital artifacts to be produced and reproduced. Previous research has portrayed boundary objects as solid and complete, thus providing little insight on production and reproduction processes, or the evolutionary nature of teamwork coordination enacted by these processes.

In the following case analysis, we were open to and considered any possible "digital artifacts" (e.g., documents, engineering diagrams, software code, etc.) as boundary objects more or less suited to particular kinds of tasks (Kallinikos et al., 2013). In addition, rather than examining the technology practices of the agents who produced the boundary objects (Kellogg et al., 2006), or the practices of the agents who receive and reproduce the boundary objects (Levina, 2005), we focused our observation on how the digital artifacts as boundary objects themselves were utilized to facilitate the processes of knowledge transference, translation, and transformation across the different boundaries, in our highly dispersed team context. 


\section{Research Methods}

In-depth case studies were undertaken to examine how virtual teams achieved knowledge coordination using digital artifacts. Case studies are most suitable when investigators have limited control over the events and boundaries of the phenomenon under investigation (as with the collective use of digital artifacts), and when the phenomenon cannot be separated from its context (as per knowledge coordination within virtual teams) (Yin, 2003). Starting with the conceptual lenses of Carlile's knowledge management framework (Carlile, 2002, 2004), and the boundary objects notion, we explored how virtual teams produced and reproduced digital artifacts to coordinate their activities. This approach is consistent with "theory elaboration" (Vaughan, 1992; Fisher and Aguinis, 2017), which refers to the process of conceptualizing and executing empirical analyses by drawing on preexisting conceptual ideas or models as a basis for generating new theoretical insights. Qualitative data were collected and analyzed using an iterative process of data examination, content coding, and comparison, with insights gleaned from the literature (Eisenhardt, 1989).

\subsection{Research Site and Sample Description}

Data were collected from a major research and development (R\&D) unit of a global Fortune 500 company, nicknamed TeleCo. This firm designed and developed a variety of telecommunications-related hardware- and software-based products and services. For example, one of TeleCo's major products was a series of asynchronous digital subscriber line (ADSL) multiplexers that were used by Internet service provider clients with differing needs for high-speed Internet access. Since it operated in the highly competitive telecommunications industry, TeleCo faced intense pressure to develop and launch reliable new product versions faster than its competitors. This pressure was translated directly into R\&D strategies that were focused on the timely production of very high-quality products, while giving due consideration to cost control and customer satisfaction. As one TeleCo project manager commented, "The biggest challenge for us is always aggressive schedules and time to market ... to provide features that the customers are looking for in a timely manner ... Of course, you always have to factor in that the customers are changing their minds because of market-driven changes. The main focus [in product development] should be on managing change according to our processes. But you're going so fast that it's difficult to follow the processes we have in place."

Thus, the TeleCo R\&D unit was expected to achieve operational excellence in terms of the product itself, as well as in the underlying processes used to create that product. To accomplish this, TeleCo relied on two types of project teams. First, feature development teams (FDTs) were responsible to deliver software feature improvements and overall product excellence-for example, reducing software complexity by minimizing product feature interdependencies. Because each FDT focused on one specific 
product feature, deep collaborative effort within and across FDTs was required. Second, process improvement teams (PITs) were responsible for designing, improving and implementing development processes. Whereas FDTs were focused on optimizing product features, PITs attended to the underlying product development processes.

Three selection criteria were employed to choose dispersed virtual teams for empirical analysis. First, team members had to experience a high degree of geographic and temporal dispersion. For more than 18 months, TeleCo had employed a dispersed model across its sites in Canada, Belgium and China, for the purpose of bringing global expertise to local customer-dependent products. Second, team tasks had to entail substantive knowledge coordination requirements. At TeleCo, development of "common features" spanning multiple products did indeed require extensive knowledge coordination between engineers from different domains. Third, virtual teams had to utilize a variety of information technologies for communication and task coordination. At TeleCo, teams utilized a shared set of technology tools such as office productivity software, email and discussion forums, document repositories, and specialized software design and development tracking systems, through which a large amount of digital artifacts were being produced and reproduced as the teams accomplish their work. A contact person within TeleCo helped to identify representative virtual teams that met our requirements. Two teams were identified: one feature development team (FDT), and one process improvement team (PIT). Each case is presented in detail as follows.

Feature Development Team (FDT): At the time of our study, the FDT's overarching goal was to develop and test a feature called "99X Extension Shelves" (hereafter referred to as "99X"), which was used to provide an interface for extended hardware functionalities. Development of this product feature required achieving three critical milestones:

(1) Hardware: timely development of a piece of a telecommunications logic board hardware in Belgium and Canada, with subsequent delivery to China;

(2) Software: timely development of a software package to support the logic board in Canada, with subsequent delivery to China; and

(3) Interface: integration of an existing application layer software package between the hardware and software to provide the product with an operational interface panel.

Once the hardware, software, and interface components were integrated, the feature required several rounds of testing, integration with the mainstream codebase, and then robust testing at the product level.

The FDT had members at all three international sites and thus faced substantial geographical and temporal dispersion. The major software and hardware engineers who developed the necessary 
components for this feature were located at the Canadian and the Belgium sites, respectively. Since this particular feature was created for a product targeted toward the Chinese market, the product testing infrastructure and activities were predominantly based at the Chinese site, to ensure that the tests conducted were "Asia-compatible." The software and test engineers in China took leading roles in testing and debugging, with assistance from the other team members. The local engineers examined bugs identified during initial testing; unresolved problems were then solved by tapping into the resources located at the other two sites.

Successful delivery of the 99X feature set therefore depended on a coordinated effort. Three particular coordination challenges were observed. First, hardware that was not originally designed to fit the unique requirements of the Chinese market had to be redesigned. Second, integrating hardware and software elements developed at geographical disparate locations was problematic. Third, because the testing work was conducted primarily at the Chinese site in order to more efficiently identify bugs related to local customers' unique requirements, an intensive coordination effort was needed to overcome team dispersion challenges. When a problem arose, it required not only the test engineer's attention, but also the support of the responsible hardware and software engineers who were located at the other sites.

The FDT relied very heavily on ICT to create and recreate digital artifacts, both internally at each site, and externally across the three sites. Microsoft Office (PowerPoint, Excel, Word, and Project) served as the dominant desktop application suite. Communication technologies included email, telephone, and teleconferencing. The team utilized on a centralized Intranet-hosted application called Project Binder to display and archive information on project status, feature development updates and major performance indicators. They also used a software package called Distributed Defect Tracking System (DDTS) ${ }^{1}$ to store and track defects and their corresponding fixes. Other tools included an automated workspace management system, a parallel development support system, and a commercial software application to manage integrated version control called ClearCase. The project team also had access to collaborative feature-testing platforms located in both China and Canada.

Process Improvement Team (PIT): The PIT's objective was to negotiate and establish a globally synchronized schematic peer review process for the development of a printed circuit board (PCB). Previously, each site had locally and independently created their own development and review processes. As TeleCo grew, it became increasingly reliant on globally dispersed feature development teams,

\footnotetext{
${ }^{1}$ DDTS is a bug-tracking system designed for software or hardware project development, quality assurance, and customer support. One popular feature of DDTS is its distributed nature that allows users to submit defects against products anywhere, anytime. DDTS includes a Web-based interface called WebTracker used for data submission and querying, as well as many different types of management reports and metrics that can provide a global view of product quality.
} 
resulting in significant inter-site coordination challenges. The PIT was commissioned to address this issue, approximately one month prior to the study, with core team members residing in Belgium, Canada and China. Successful project delivery required the PIT to address two overarching challenges:

(1) consolidating cross-site hardware standards, which was particularly problematic as Canada had previously operated as an independent firm and had only recently been acquired by TeleCo; and (2) consolidating ambiguous working documents arising from organizational and contextual differences across the three sites.

Like other virtual teams in TeleCo, this PIT heavily relied on digital artifacts to coordinate knowledge and was particularly reliant on the Microsoft Office application suite. The primary means of communication among team members, both within and between sites, was corporate email messaging, supplemented by occasional telephone or conference calls. The Intranet served as a structured storage device and was used to archive and share project status reports, meeting minutes, and document updates, all of which were accompanied by detailed comments from team members. The major digital artifacts that were routinely produced and exchanged within this team included email messages, presentations, status reports, estimates, working documents, and project schedules. These artifacts were further supplemented by Intranet-hosted web pages, which provided additional organization and project team information on demand. Team characteristics are provided in Table 1. 
Table 1: Team Characteristics

Feature Development Team (FDT)

Process Improvement Team (PIT)

\begin{tabular}{|c|c|c|}
\hline $\begin{array}{l}\text { Contextual } \\
\text { Conditions }\end{array}$ & $\begin{array}{l}\text { - Three geographically dispersed sites } \\
\text { - Three time zone differences } \\
\text { - Three different functions }\end{array}$ & $\begin{array}{l}\text { - Three geographically dispersed sites } \\
\text { - Three time zone differences } \\
\text { - Two different functions }\end{array}$ \\
\hline Project Goal & $\begin{array}{l}\text { - To develop and test a feature called } \\
\text { 99X Extension Shelves }\end{array}$ & $\begin{array}{l}\text { - To develop and implement a universal } \\
\text { peer review process for printed circuit } \\
\text { board schematics }\end{array}$ \\
\hline Composition & $\begin{array}{l}\text { - Two hardware designers } \\
\text { - Two software developers } \\
\text { - One testing engineer }\end{array}$ & $\begin{array}{l}\text { - Three process engineers } \\
\text { - One hardware engineer }\end{array}$ \\
\hline $\begin{array}{l}\text { Major } \\
\text { Knowledge } \\
\text { Coordination } \\
\text { Issues }\end{array}$ & $\begin{array}{l}\text { - Collectively revising hardware } \\
\text { - Integrating hardware, software and } \\
\text { application layer software } \\
\text { - Cross-site testing and debugging }\end{array}$ & $\begin{array}{l}\text { - Consolidating different HW processes } \\
\text { - Clarifying ambiguity in working } \\
\text { documents }\end{array}$ \\
\hline ICT Tools & $\begin{array}{l}\text { - Email } \\
\text { - Document repository on the Intranet } \\
\text { - Office productivity tools } \\
\text { (PPT, Excel, Word, Project) } \\
\text { - Project Binder } \\
\text { - Distributed Defect Tracking System } \\
\text { - Automatic work space } \\
\text { - Version control system (ClearCase) } \\
\text { - Testing console } \\
\text { - Phone facilities }\end{array}$ & $\begin{array}{l}\text { - Email } \\
\text { - Document repository on the Intranet } \\
\text { - Office productivity tools } \\
\text { (PPT, Excel, Word, Project) } \\
\text { - Phone facilities }\end{array}$ \\
\hline $\begin{array}{l}\text { Digital } \\
\text { Artifacts }\end{array}$ & $\begin{array}{l}\text { - Email text message } \\
\text { - Electronic documents } \\
\text { (reports, presentations, spreadsheets) } \\
\text { - Intranet web pages } \\
\text { - Hardware specifications } \\
\text { - Software programs and code }\end{array}$ & $\begin{array}{l}\text { - Email text message } \\
\text { - Electronic documents } \\
\text { (reports, presentations, spreadsheets, } \\
\text { process specifications, schedules) } \\
\text { - Intranet web pages } \\
\text { - Project portal (binder) }\end{array}$ \\
\hline
\end{tabular}

\subsection{Data Collection}

Qualitative data were collected over a nine-month period. Virtual teams were directly observed for eight hours per day during a twenty-four-day site visit to TeleCo's Chinese offices, a twelve-day visit to TeleCo's Canadian offices, and virtually for TeleCo's Belgium offices. As summarized in Table 2, qualitative data sources included 15 on-site meetings, 14 multi-site audio conferences, six focus group interviews, 58 individual interviews (ranging from 45-80 minutes in length, each recorded, transcribed, and validated by the subject), approximately 1,200 email messages sent/received between team members during the nine-month study period, and a wide range of informal interactions (e.g., day-to-day communications as team members worked in their cubicles, took coffee and lunch breaks, attended lunch- 
and-learn seminars, and took part in various social events). An example of the fieldwork log is presented in the Appendix.

Table 2: Qualitative Data Sources

\begin{tabular}{|c|c|c|c|c|}
\hline Source & Canada & China & Belgium & Total \\
\hline Informal interaction (days on site) & 12 & 24 & $\mathrm{~N} / \mathrm{A}$ & 36 \\
\hline Document archives & \multicolumn{3}{|c|}{$\begin{array}{l}\text { Intranet pages, meeting minutes, product } \\
\text { specifications, project work in progress }\end{array}$} & $\begin{array}{c}5,000+ \\
\text { pages }\end{array}$ \\
\hline Direct observation - on-site meetings & 5 & 10 & N/A & 15 \\
\hline Direct observation - audio conference & 6 & 8 & N/A & 14 \\
\hline Focus group interviews & 4 & 1 & 1 & 6 \\
\hline Individual interviews - semi-structured & 6 & 12 & 12 & 30 \\
\hline Individual interviews - unstructured & 15 & 10 & 3 & 28 \\
\hline $\begin{aligned} \text { Email exchanges } & \text { - received } \\
& - \text { sent }\end{aligned}$ & $\begin{array}{l}232 \\
219\end{array}$ & $\begin{array}{l}279 \\
223\end{array}$ & $\begin{array}{l}123 \\
109\end{array}$ & $\begin{array}{l}634 \\
551\end{array}$ \\
\hline
\end{tabular}

Data collection efforts were focused on soliciting participants' general views about their team's boundary characteristics, project statuses, goals, specific tasks, task-related knowledge, and use of ICT. To account for the wider organizational context, internal broadcast emails (e.g., recent company news, annual performance briefings, and strategic initiative circulars) were reviewed throughout the study period. Two types of document archives were examined: (1) pre-existing electronic documentation related to the focal teams (e.g., team member profiles and contact information, meeting minutes, project reports and presentations, status reports, working documents, personnel reviews, performance evaluations, local mission and strategic statements, organizational charts, newsletters, and records of recent events); and (2) documents that emerged during current team interactions (e.g., shared files, corporate intranet links). Data were also collected on subjects' "everyday activities", especially those that were intellectually and/or practically challenging or stimulating.

\subsection{Data Coding Procedure}

An iterative, open-ended approach was used to code and analyze the qualitative data (Eisenhardt, 1989). Guided by the theory elaboration approach (Vaughan, 1992; Fisher \& Aguinis, 2017), concepts related to digital artifact coordination and boundary objects were continuously elicited and incorporated into the analysis (Carlile, 2004). Coding proceeded in three stages.

First, an open coding technique was used to concentrate on work practices undertaken by team members in their everyday collaborative work. Team members were asked to describe occasions when they experienced a challenge such as a technical difficulty, critical deadline, misunderstanding or 
misalignment of actions, and then to explain how the problem was solved. Critical events of this nature surfaced latent knowledge coordination problems, thereby helping us identify technology practices that would have been unseen in more common situations. Open coding was applied to practices such as "receive email," "send email," "publish to the Intranet," “access the Intranet," "compose email," "fill in online forms," and "create an online document plan"-in other words, practices that involved engagement with digital artifacts.

Second, axial coding was used to aggregate these practices into higher-level categories, through inductive and deductive analyses, based on whether the practices spanned the syntactic, semantic or pragmatic boundaries (Carlile, 2004; Fisher \& Aguinis, 2017). For example, axial coding was conducted by relating items such as "send/receive/read email" and "access the internet" as these practices both spanned syntactic boundaries. An additional category was prepared for practices that did not fit into any of the three kinds of knowledge boundary spanning practice categories. Then, we further examined commonalities and differences between these practices to abstract higher level concepts. For example, the practices "receive email" and "access the internet" were labeled as "practices of accessing" since they had to do with members accessing digital artifacts produced by others.

Finally, selective coding was applied. Ongoing work activities and digital artifacts were further evaluated as virtual team members produced, exchanged, and reproduced artifacts, in the midst of a constantly evolving social/technical fabric (Eisenhardt, 1989). Selective coding was achieved by iteratively categorizing the practices to the higher-level constructs. For example, when "accessing" practices were identified, we looked for and categorized related practices such as "keep an eye on", "kept in the loop", "check this document" and "look up the database". Selective coding helps validate that the practices observed during the open coding procedure belong to only one, and not multiple, categories.

The coding procedures were initially and broadly guided by Carlile's $(2002,2004)$ theoretical framework, but new concepts and practices were also allowed to surface. Through iterations between open, axial, and selective coding, additional categories and subcategories of practices did emerge, and were linked with different levels of knowledge coordination together. This approach is consistent with Eisenhardt's (1989) technical recommendations for case analysis.

\section{Data Analysis and Results}

Geographic, domain, and functional differences between teams are summarized in Table 3. Cases describing observed knowledge coordination practices of the virtual teams are then presented separately, followed by an analytical overview. 
Table 3: Team Composition

\begin{tabular}{|l|l|l|l|}
\hline \multirow{4}{*}{ Team } & Function & Project Roles \& Responsibilities & \multicolumn{2}{l|}{ Location } \\
\cline { 2 - 4 } & Hardware designer (Tom) & $\begin{array}{l}\text { Delivered BOARD specifications } \\
\text { customized to the Asian market }\end{array}$ & Canada \\
\cline { 2 - 5 } & Software developer (Andrew) & Developed BSP software & Canada \\
\cline { 2 - 5 } & Software developer (Sam) & $\begin{array}{l}\text { Integrated and tested the application } \\
\text { layer software with BSP and BOARD }\end{array}$ & China \\
\cline { 2 - 5 } & Test engineer (Lee) & Led feature test & China \\
\cline { 2 - 5 } & Hardware designer (Billy) & $\begin{array}{l}\text { Supported the Canadian HW designer } \\
\text { on BOARD customization }\end{array}$ & Belgium \\
\hline \multirow{4}{*}{ PIT } & Process manager (Eric) & Served as project leader & Belgium \\
\cline { 2 - 5 } & Hardware engineer (Moore) & Provided functional expertise & Belgium \\
\cline { 2 - 5 } & Process engineer (Jack) & Provided local support & China \\
\cline { 2 - 5 } & Process engineer (Anthony) & Provided local support & Canada \\
\hline
\end{tabular}

\subsection{Technology Practices in the Feature Development Team (FDT)}

Knowledge Transfer. The feature development project team constantly faced tight deadlines. As the project manager explained, "I saw that it was again time to [go to] market ... There was a lot of pressure to stay on schedule because there were huge penalties from the customer [for missed schedules]." To keep the project moving quickly and in a coordinated manner, team members relied daily on email messages and the Project Binder to codify, upload, and share their work with their temporally and geographically separated colleagues. Such use of digital artifacts is consistent with what Carlile (2004) described as knowledge transfer. However, we also observed that in order to complete knowledge transfer through these digital artifacts, two distinct technology practices were required. First, team members needed to proactively send and publicize the artifact to their remote peers. Second, remote peers needed to accept and absorb the artifact content. The activities associated with sending and receiving digital artifacts we labeled as presenting and accessing practices. One local project manager explained a common digital artifact interaction this way: "When the engineers take a piece of code and they read it and find, say, ten defects, they fill in an electronic form that goes into the data warehouse and then I get the metrics on the Project Binder." These kinds of presenting and accessing practices often appear simple and commonplace, yet they are essential to coordinating virtual team knowledge contained in digital artifacts, as they are transmitted across space and time.

Knowledge Translation. During the coding process we observed occurrences of what Carlile (2004) described as knowledge translation, and here again digital artifacts played an instrumental role. 
Specifically, the sender would sometimes adjust the digital artifact in such ways that explicitly invited additional inputs from the receiver, who in turn took advantage of this adjusted artifact to provide his/her inputs, through which knowledge from different parties were embedded into the digital artifact (Griffith et al., 2003). For instance, a Canadian hardware engineer named Tom was in charge of delivering the hardware component by coordinating with Billy, a Belgian engineer who originally designed the hardware for the North American market. Billy had full read-and-write privileges with respect to the current hardware specifications stored on the Project Binder, and he in turn granted these privileges to Tom. Billy also took time to highlight some of the hardware specifications that he thought might be different across regions, with the apparent intention of drawing Tom's attention to those specifications. Furthermore, Billy prepared notes containing additional detail. In making these adjustments to the artifact, Billy invited Tom to reflect and engage with the digital artifact (e.g., hardware specifications). Tom responded to Billy's call for attention by accessing the Project Binder and providing new content, without destroying any of the existing content. Specifically, as Tom explored strategies to adapt the product to the Asian market, he re-examined the hardware, considered specification differences between North America and Asia, and added new material to the artifact by expanding the schematics to allow for the plug-in of Asian-specific features. We labeled this practice pair representing and adding: Billy highlighted and represented the original digital artifact to Tom, who expanded it by "adding" new content. By first representing and promoting a digital artifact, and then adding to its existing content, these team members engaged in knowledge translation.

Knowledge Transformation. A third pair of practices was observed that was consistent with Carlile's (2004) knowledge transformation concept. At one point, the FDT faced a technical challenge after all the components had been fully assembled and the work had reached the final "black-box" feature testing stage. Testing activities had initially proceeded smoothly, but a testing engineer in China named Lee suddenly discovered an incompatibility issue. Lee contacted a software engineer in China (Sam), and also turned to hardware engineers (Billy, Tom) and a software engineer (Andrew) from the other two sites to help resolve the problem. The problem was complex and serious, and the team was forced to delay project delivery. The Canadian engineers tried, unsuccessfully, to replicate the bug using their own hardware, software, and interface testing platform. The team then engaged in multiple teleconference meetings during which Lee operated the local testing platforms according to instructions given by the remote members, but bug replication was again unsuccessful. As a last resort, Lee provided his international peers with remote access to the Chinese testing platform, and this finally allowed the remote engineers to replicate the bug so they could begin to develop a solution. According to Lee, "Testing and debugging are more complex because the testing platforms [across sites] are slightly different in specifics. What we did 
was to restore the problem scenario at the client's modem and give access to Antwerp [the Belgium site], so that they can access and make changes. We don't do this often, but once we do, it usually works well."

These emergent knowledge transformation practices were different and substantially more involved than the presenting-accessing and representing-adding practices previously observed. For one thing, the artifact's authorization and read-write privileges had to be (temporarily) reset, which required a departure from standard protocol and an increased security risk. For another, providing remote engineers low-level access to local servers required a symbolic and literal "handing off" of operational control. On reflection, we labeled these practices as molding and challenging. When local engineers opened up the local artifact and related technology resources for remote access in order to solve a serious problem, they stepped away from standard operating procedures and molded a new non-standard practice. On the other hand, when the remote engineers accessed, critically assessed, and fundamentally modified the code to resolve the problem, they effectively challenged the digital artifact. Interestingly, once the engineers understood the root cause of the problem, they picked up and reused most of the bug detection routines that Lee had already attempted locally, and revised other routines according to testing priorities. According to Tom, "The remote access really gave you the latitude to work directly on the problem and make changes. At the same time, they [remote engineers] could see what you did." Using this remote diagnosis and debug capacity, it took the team two weeks to trace back and identify the root cause by revisiting, decomposing, and re-integrating the application, before the project started to move forward again.

Knowledge Holding. An additional finding of note here relates to the team's use of withholding and ignoring practices. When FDT members realized they could not deliver on all the promised features by the deadline, they called for emergency meetings and aggressively re-scoped the project by prioritizing the most-wanted features, and temporarily setting aside low-priority features and associated feature progress reports. The intention was to re-engage the lower-priority features once the urgency had passed. During this emergency phase, members actively withheld certain artifacts (e.g., they chose not to distribute certain artifacts to other members), and ignored certain artifacts (e.g., if they judged them to be related to lower-priority features). According to one team member, "a problem commonly raised regarding email is that people don't respond ... maybe because they have so many emails to reply to.". These practices, which we labeled as withholding and ignoring, were tacitly agreed upon and accepted by the team, and were generally functional and positive practices.

To summarize, the FDT used presenting and accessing practices to support knowledge transfer, representing and adding practices to support knowledge translation, and molding and challenging practices to support knowledge transformation. They also engaged in withholding and ignoring practices, with apparently beneficial results. We used this set of newly termed concepts as a tentative conceptual 
lens to observe a second team at TeleCo. In doing so, we looked for both supporting and contradictory examples, as well as additional concepts to emerge.

\subsection{Technology Practices in the Process Improvement Team (PIT)}

Knowledge Transfer. The most prevalent practices observed in the PIT were related to presenting and accessing digital artifacts, as dispersed team members shared digital documents and charts to keep each other synchronized across time and space boundaries. For instance, Eric routinely sent email and project schedule artifacts (presenting), which other members opened and reviewed to "stay in the loop" (accessing). Another team member explained that she always uploaded her work-in-progress to the Weblibrary (Weblib) section of the Project Binder, so that her team members would be able to access and take over her work. These findings were very consistent with what we observed in the FDT.

Knowledge Translation. Representing and adding practices, associated with knowledge translation, were also frequently observed in the PIT. This team was responsible for formally proposing process improvement projects for upper management approval. In the early stages of one project, process manager Eric searched the Weblib system, found an existing proposal in PowerPoint format, and used it as a template - thus engaging in an adding practice. This template included categories such as scope, expected benefits, required effort, deliverables, and timelines; as Eric explained, these PowerPoint documents were intentionally structured to enable members to quickly and easily review and understand details, and then offer additional content - thus supporting the representing practice. Similarly, team members' use of digital artifacts such as Project Binders and Microsoft Office templates normalized the representing and adding of information across projects and development sites, enabling members to articulate and simplify their contributions in a manner that made their work interpretable to other people anywhere at any time. Another example of representing and adding was seen when member Eric submitted the project proposal by uploading the document to the Weblib shared document system. Moore, Anthony and Jack were listed as authors, and were subsequently sent an email invitation along with an embedded link to the document. These three read the proposal and provided feedback at predefined places in the template. Each time a new version was submitted, Eric received an email with a link to the related web page indicating that a review update was available. As one member noted, "Basically the way Weblib works is that we upload a work-in-progress [document], often in PPT format, and assign particular people to review it by putting in comments. Whoever is given the responsibility is supposed to give comments. The case cannot be closed until the document owner responded to the review by putting a response in Weblib." Thus, representing and adding were performed incrementally and constantly in the day-to-day coordination of this dispersed team. 
Knowledge Transformation. As in the FDT, PIT members engaged in knowledge transformation via molding and challenging practices. As one example, once upper management approved the project described above, Moore (from Belgium) offered to draft the initial process document in the form of a PowerPoint slide deck and share it via Weblib. Again, this document was considered to be a work-inprogress, and in-depth engagement and revisions (molding) was expected from the partner sites. The other two sites responded to the document in different ways. The Chinese site was preoccupied with preparing for a cross-site Capability Maturity Model Integration (CMMI) test, so time available for this project was limited. There was also a misconception at the China site that the hardware review processes were already consistent between Belgium and China. Jack (from China) reported: “Our process was historically adopted from Belgium, thus initially we assumed there should not be big inconsistencies or conflicts. We passed the review pretty quickly." Jack quickly accessed the document, but he did not engage the busy local hardware engineers or ask them to review and critique the process document, even though such consultation was normally done for process improvement initiatives. When Jack later presented the finalized process to the group of local Chinese hardware engineers, who were the end users of this redesigned process, they responded negatively and challenged the product's feasibility and adaptability. Many opposed the idea of using the comment functionality in Weblib for every step of the review, because over time the Chinese engineers had grown accustomed to using email for iterative commenting purposes. Similarly, they disliked the monthly schedule of three-party meetings that would require them to sacrifice their evenings, which they preferred to reserve for family time. This forced Jack to revisit the document and contact Eric (in Belgium) and Anthony (in Canada) to negotiate additional changes to the final product (molding), which led to a four-week delay in final delivery. While this episode may on one level appear to describe a failed process, it was resistance from the community (challenging), and Jack's responsiveness to that feedback by re-engaging the engineers (molding), that led to a successful resolution.

Meanwhile, the process document initiated by the Belgian site drew significant attention at the (previously independent) Canadian site immediately after it was shared. As a new participant in TeleCo, the Canadian site was becoming increasingly aware that their existing processes had to be changed. Anthony actively engaged Canadian hardware engineers for concerns and comments by setting up a series of local discussion meetings, then consolidated the comments and suggestions. Based on these local inputs, he frequently requested clarification and reinterpretation and continuously provided local information via other digital artifacts like email and Weblib (adding), and demanded revisions that were more consistent with local practices and interests at the Canada site by directly marking changes on the process documents (challenging). He later reported, "Instead of explaining what I meant by phone, I feel it is most effective to just simply get my hands dirty [with the PowerPoint document] ... I changed the 
slides to the way I think would work the best and commented on those that I was not one hundred percent sure about. Then I sent it back for them to read." During nearly two weeks of time-consuming interactions around these practices, the artifact gradually became acceptable to the Canada site. As a result of this coordination effort, the Canadian and Belgian sites achieved provisional agreement from local hardware engineers on deliverables, and the final document was readily accepted at the Canadian site when it was finally rolled out. In this case, molding and challenging were repeatedly and consistently implemented in response to the coordination requirement of integrating local preferences into the global document.

Knowledge Holding. As with the FDT, withholding and ignoring practices were observed in the PIT, and also assisted positively with team coordination. In order to quickly finish off the current project and save time for other priorities, Jack simplified coordination with the Belgium site by ignoring (or at best responding superficially to) Moore's requests for comments, until the quality problem was finally red flagged by the Chinese hardware engineers. Members in these virtual teams dealt with an overwhelming number of emails every day. In order to keep key stakeholders satisfied, they had to suspend certain lowpriority coordination work by selectively ignoring emails and focusing on those that were immediately related to high priority work, sent by the most relevant people (e.g., supervisors and close peers). As Anthony put it: "Otherwise, you end up spending most of your time typing emails and [you're] still not able to leave the office on time."

\subsection{Analytical Overview}

The case studies described above reveal four pairs of technology practices involving digital artifacts in use by dispersed teams. We found most of these practices to be highly consistent with Carlile's (2004) knowledge management framework. First, the paired production-reproduction practices of presenting and accessing reflected the simplest and most common approach to knowledge coordination: transferring dispersed knowledge among virtual team members via digital artifacts. In this mode, a member at one site would present a new digital artifact to team member(s), for example, by constructing a review status update and sharing it with remote teammates using one or more communication technologies, such as a group mailing list via Microsoft Outlook. The recipient(s) would then access the digital artifact — that is, they received, opened, read and evaluated the status update. These two practices were suitable for spanning geographical and temporal boundaries, because they allowed boundary objects to serve as an around-the-clock "broker" that faithfully relayed information among team members and bridged the gaps in time and space.

The second paired production-reproduction practices entailed a somewhat more complex approach to knowledge coordination. Through representing, members actively sought to make their work 
interpretable by others. Rather than simply forwarding raw work output, this practice entailed constructing digital artifacts in a way that was intentionally meaningful, legible and open from the recipient's point of view. Meanwhile, recipients of the artifact engaged in adding. This involved going beyond simply accessing the artifact (e.g., receiving, opening, reading, evaluating). Instead, the recipient was deeply engaging, enriching, and advancing the digital artifact's content. Thus, knowledge coordination across sites was accomplished by combining dispersed resources through an accumulation of content that was contained within an explicit digital artifact. The paired practices of representing and adding spanned not only geographical and temporal boundaries, but also semantic boundaries, by accommodating and combining dispersed knowledge originating from different functions and sites.

The third paired production-reproduction practices represented the most complex approach to knowledge coordination in virtual teams. When molding, a member produced a digital artifact at one site and made it available to remote sites, such that others were invited and empowered to fundamentally revise and refine its essential meaning and structure. When remote recipients engaged in challenging, they would constructively "push back" or override predefined rules using their own judgment, experiences and local resources - for example, by introducing relevant local knowledge that challenged pre-existing assumptions. This process integrated dispersed resources by developing a negotiated balance of what should be prioritized between multiple parties.

The fourth pair of technology practices we observed, withholding and ignoring, have not been reported in prior work. They represented purposeful decisions not to engage in knowledge coordination behaviors. By withholding a digital artifact, an individual chose to hold onto the artifact rather than making it available to other team members. Likewise, by ignoring an existing digital artifact, the individual refused to accept, open or otherwise engage with an artifact that had been sent to them. In general, withholding and ignoring practices do not promote knowledge coordination, yet we did find incidents where these activities were purposely enacted as part of the larger knowledge management strategy. We consolidated these empirical findings into a conceptual model, building onto Carlile's (2004) original model, as illustrated in Figure 1. 


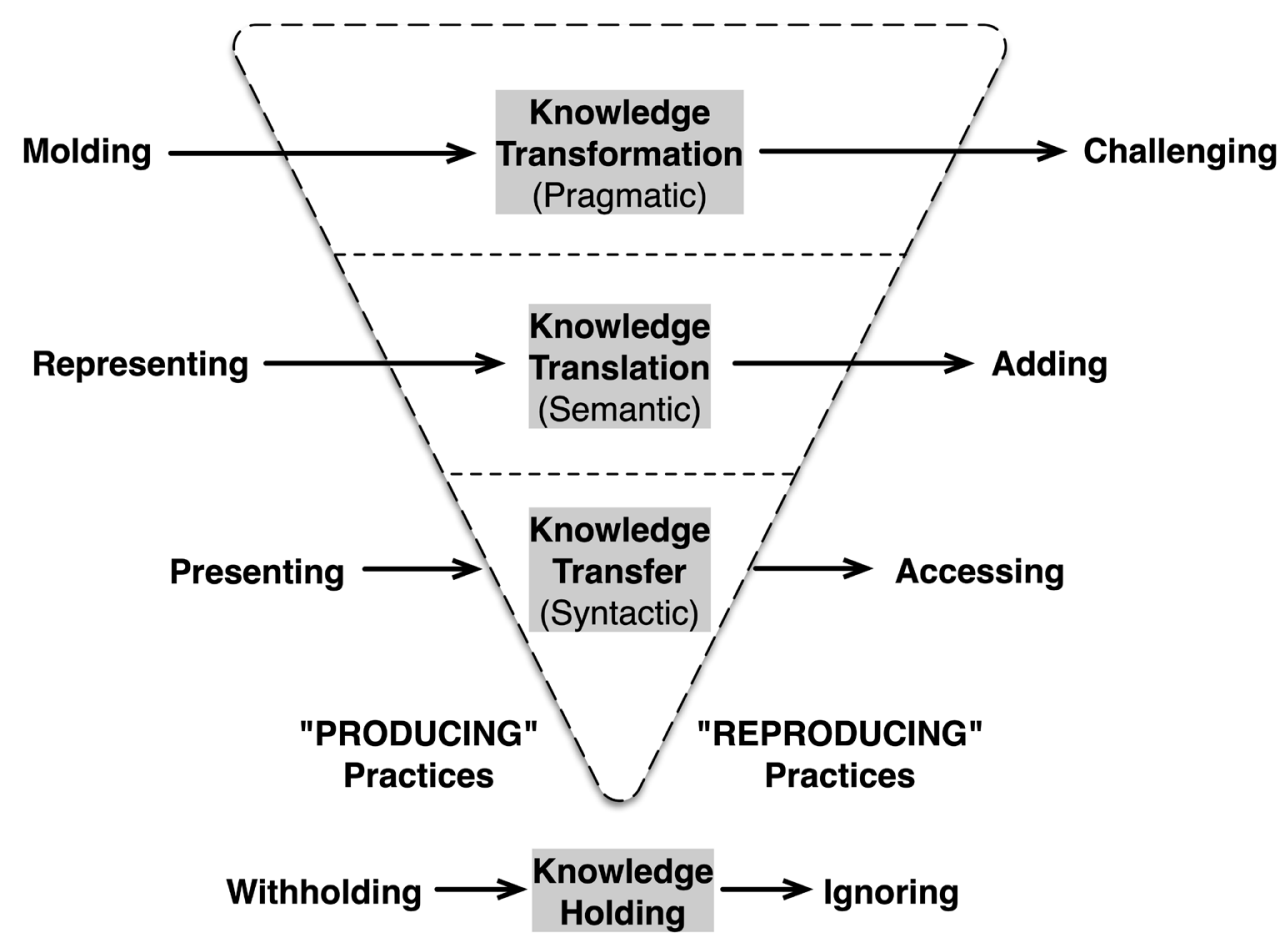

Figure 1 - A Conceptual Model for Knowledge Coordination via Digital Artifacts in Highly Dispersed Teams

\section{Discussion}

Increasing reliance on highly dispersed teamwork calls for a more fine-grained understanding of complex distributed organizing practices. This in-depth case study offers a more nuanced explanation about the ways that dispersed teams coordinate knowledge through digital artifacts. Interpreting our case study results through the lens of Carlile's $(2002,2004)$ knowledge management framework, along with the notion of digital artifacts (Arazy et al., 2020; Ekbia, 2009; Kallinikos et al., 2013) as boundary objects, we argue knowledge coordination in geographically and temporally dispersed teams can be understood through team members' collective production and reproduction of digital artifacts. Our analysis identified four sets of technology practices that team members used to collectively structure digital artifacts, related to knowledge transfer (presenting-accessing), knowledge translation (representing-adding), knowledge transformation (molding-challenging), and knowledge holding (withholding-ignoring).

We observed that the level of knowledge coordination, from transference, to translation, to transformation was progressively complex. Basic knowledge transfer involved transferring the digital artifacts "as is" without content changes. As one local project manager in FDT stated, "When the engineers take a piece of code and they read it and find, say, ten defects, they fill in an electronic form that goes into the data warehouse and then I get the metrics on the Project Binder. And so it's very 
efficient." Practices associated with knowledge translation were more complex, requiring digital artifacts to be added to while preserving their original content. For example, in the PIT project, PowerPoint templates were intentionally structured so that, when they were circulated for review, other members could quickly and easily understand the specifics and offer additional content. And the practices related to knowledge transformation required digital artifacts to be fundamentally reconstructed. As explained by the test engineer in the FDT, "Testing and debugging are more complex because the testing platforms [across sites] are slightly different in specifics. What we did was to restore the problem scenario at the client's modem and give access to Antwerp [the Belgium site], so that they can access and make changes. We don't do this often, but once we do, it usually works well." The ongoing, recursive nature of these knowledge coordination activities, resulting from the emergent use of the corresponding technology practices, enabled the dispersed teams to move their work forward, eventually accomplishing their team objectives.

Identification of a fourth pair of practices associated with holding back knowledge (withholdingignoring) was unexpected. Whereas the first three pairs of practices were used to enable knowledge coordination at different boundaries, withholding and ignoring were used to both delay and facilitate knowledge coordination. While ignoring behaviors have been discussed in the collaborative systems development literature (Levina, 2005), what is new here is the practice of withholding as the counterpart to ignoring. Withholding occurs when people keep digital artifacts from remote team members, perhaps due to encoding difficulty (e.g., physical artifacts that are difficult to digitalize), lack of awareness (e.g., assumption that the remote party already has access to the digital artifact, or failure / forgetfulness to transmit), or lack of competence (e.g., poor quality in constructing the digital artifact). We also observed that withholding can occur with full intentionality, as was the case with the TeleCo teams who set access restrictions on certain digital artifacts or reserved them locally.

Management scholars have argued that knowledge withholding impedes team processes (e.g., process capabilities) and team outcomes such as performance (Evans et al., 2015). In the current study, however, withholding practices were used to facilitate knowledge coordination. As with ignoring, withholding should not be simplistically understood as a dysfunctional practice. By setting appropriate access privileges, TeleCo teams made digital artifacts accessible to select personnel, and contributed positively to coordination by eliminating excessive information exposure and unnecessary communication overhead. While the practices of withholding and ignoring actually do not pertain to spanning any kind of knowledge boundary, they might be particularly salient for contemporary distributed teams as information overload has become an issue with the proliferation of new ICT tools (Ellwart et al., 2015). In urgent situations, temporary withholding and ignoring practices may be a valid strategy for managing information overload. 
Withholding digital artifacts may also be relevant to offshoring, where practices such as "routing tasks strategically" and "filtering quality" (Leonardi \& Bailey, 2008) have been shown to help coordinate knowledge work across sites.

\subsection{Theoretical Contributions}

First, this study contributes to the literature on knowledge coordination, particularly related to virtual teams, by examining the role of digital artifacts. The ways in which various IT artifacts can enable knowledge coordination in teams has been discussed extensively in the literature, primarily by focusing on IT artifacts as tools (Choi et al., 2010; Iyengar et al., 2015; Romanow et al., 2018). This paper provides a fresh perspective on knowledge coordination by examining a different set of IT artifacts, namely digital artifacts. We argue that technology practices - what people and teams actually do every day with their digital artifacts - are critical in this examination. By adopting technology practice as the unit of analysis, this paper establishes the collective production and reproduction of digital artifacts as a central mechanism for coordinating dispersed knowledge and reveals that each of the four modes of paired technology practices can enable virtual teams to structure digital artifacts for a particular type of distributed knowledge coordination. The four sets of practices provide a deeper understanding of how knowledge coordination is achieved in highly dispersed teams.

Second, this work connects with and adds to the literature on boundary objects. Previous literature has considered boundary objects either as "technological artifacts" with predetermined properties (e.g., Carlilie 2002), or as "technologies-in-practice" dichotomized as use versus non-use (e.g., Barrett \& Oborn, 2010; Levina \& Vaast 2005). In contrast, this paper focused on the role of digital artifacts, which are quasi-products always in the making (Kallinikos et al. 2013), and examined how the practices of production and reproduction of boundary objects impacted knowledge coordination. In so doing it also offered an explanation about how knowledge spanning activities, that in traditional context occur primarily through direct face-to-face interactions, operate in the virtual team context.

Third, this paper contributes to Carlile (2004)'s knowledge management framework by extending its application from the collocated team context, to the distributed team. Carlile's (2004) framework mainly addresses the knowledge interdependency challenges in collocated work context where knowledge boundaries occur. In the collocated context, knowledge boundary spanning activities occur primarily through direct face-to-face interactions, yet this operates differently for virtual teams. The current study extends the applicability of the framework to shed light on knowledge coordination in virtual teams by identifying technology practices in the production and reproduction of digital artifacts unique in virtual team environments. 
Moreover, the study reveals an additional set of practices, withholding and ignoring, that has been neglected in the literature on knowledge coordination. Previous studies have identified information hiding or withholding in gatekeeping and brokering practices (e.g., Mehta \& Bharadwaj 2015), but these studies were focused on these phenomena across teams, either from outside stakeholders toward the team, or from inside the team to outside stakeholders, rather than within team activity. The current study extends this line of research from the meso level (e.g., inter-team) to the micro level (e.g., intra-team). Moreover, while previous studies that have focused exclusively on negative effects from withholding and ignoring activities (Evans et al., 2015), our results suggest these activities may play a positive role in knowledge coordination, particularly in the virtual context where members rely heavily on digital artifacts and where information overload is common (Ellwart et al., 2015). Results suggest that research on IT-based knowledge management should not omit the practice of withholding from its analysis. Clearly, more research is needed in this area.

Finally, this paper broadly responds to the literature on IT artifacts. Orlikowski and Iacono (2001) charged that IS research has failed to engage with its "core subject matter-the information technology (IT) artifacts" (p. 121), but to date only limited research has answered this criticism (Faulkner \& Runde, 2017). This study begins to open up the "black box" of knowledge coordination through technology practices embedded in digital artifacts. This view on practice is consistent with Barrett and Oborn's (2010) call to examine the role of IT artifacts from an emergent perspective.

\subsection{Practical Contributions}

Two important implications for practice are proposed. First, digital artifacts can and should be used differently by distributed teams versus collocated teams, with varying levels of associated knowledge coordination complexity. Effective knowledge coordination in virtual teams is not simply collaborating by "passing along information"; rather it involves the production and reproduction of digital artifacts through a variety of practices. Focusing on these practices could allow organizational and team leaders to substantially improve knowledge coordination effectiveness, and performance. Leaders and members of virtual teams should be consciously aware of what practices they are engaging in with a given digital artifact, as the same artifact can support multiple different practices.

Second, members should clearly express expectations about how digital artifacts ought to be used for collaborating, otherwise the sender and recipient of a coordinating artifact may treat it in differing and unanticipated ways. This means that if the sender wishes to engage in knowledge transfer (presentingaccessing), knowledge translation (representing-adding), or knowledge transformation (moldingchallenging), they should invite the recipient to engage with the digital artifact in the expected way. The 
clear expression of expectations will help team members prevent misunderstandings and misinterpretations, and to interact and coordinate more efficiently and effectively.

Third, virtual team practitioners should use the practices of withholding and ignoring carefully and strategically, to facilitate rather than impede knowledge coordination. Specifically, mangers and team leaders should be aware that not all practices related to withholding and ignoring are dysfunctional. Figuring out and differentiating the situations in which withholding and ignoring may facilitate improved knowledge coordination is an important and valuable tool. When this set of practices is adopted for knowledge coordination, they should be ready to address concerns as they occur, by using appropriate techniques such as providing explanations to team members.

\subsection{Limitations and Future Research}

One frequent criticism of case-based, qualitative, theory-building research is that the sample size is too small to demonstrate external validity. While the context of this study is two virtual teams in one global organization, the focus of analysis is on the practices of team members. We conducted theoretical sampling on what members do with digital artifacts, thus at the behavioral level of practices (identified through dozens of informal interactions and meeting observations, 1200 email messages, and thousands of pages of archival document review per Table 2), the "sample" used in this study was not small, but rather suggests strong support for design validity (Venkatesh et al., 2013).

Future research can examine how the technology practices identified here unfold temporally, and the subsequent virtual team performance impacts. This consideration would require more explicit treatment of the process perspective that can provide "a rich explanation of how and why the outcomes occur when they do occur" (Markus \& Robey, 1988, p. 595), with an emphasis on sequences of events (Burton-Jones et al., 2014). Building on the findings of our study, this future endeavor could further develop emergent practice theories in virtual teams, as exemplified by some earlier studies (e.g., Okhuysen \& Bechky, 2009; Seidel \& O'Mahony, 2014). Researchers might investigate how improvisation plays a role in these practices.

Finally, the practice pairs identified here are closely related to the characteristics of digital artifacts (Kallinikos et al., 2013). For example, if a digital artifact cannot be distributed or modified, the practices of molding and challenging are impossible. Future research could further examine the connections among practices to understand how specific characteristics might be enacted more productively for certain practices and boundaries versus others, across varying contexts. Some other interesting questions include: Are more complex forms of production-reproduction always superior, or are simpler forms appropriate in some situations? Can the sender and receiver be matched in order to optimally coordinate and utilize the 
knowledge? How should a firm's IT infrastructure be designed so as to promote selection of the most effective knowledge coordination practices? Future studies could also investigate the potential moderators that might influence the effectiveness of the practices, such as task characteristics or individual behavioral preferences (e.g., related to personality factors), as well as the existence of other types of technology practices related to digital artifacts (e.g., are there additional abstraction levels?).

\section{Conclusion}

Theorizing on knowledge coordination has helped us to further open the black box of distributed teamwork by closely examining how dispersed knowledge gets coordinated in geographically and temporally dispersed product development teams. This provides a better understanding of the role of digital artifacts in the coordination process, the interacting relationships between digital artifacts and virtual team members, and the emergent knowledge coordination outcomes of such interactions. This paper contributes to the literature by supplementing a process-oriented, emergent view of knowledge coordination, with a central focus on usage of digital artifacts. 


\section{References:}

Alavi, M. \& Tiwana, A. (2002). Knowledge integration in virtual teams: The potential role of KMS. Journal of the American Society for Information Science and Technology, 53, 1029-1037.

Alsharo, M., Gregg, D., \& Ramirez, R. (2017). Virtual team effectiveness: The role of knowledge sharing and trust. Information \& Management, 54, 479-490.

Arazy, O., Lindberg, A., Rezaei, M., \& Samorani, M. (2020). The evolutionary trajectories of peerproduced artifacts: Group composition, the trajectories' exploration, and the quality of artifacts. MIS Quarterly, 44, 2013-2053.

Barrett, M. \& Oborn, E. (2010). Boundary object use in cross-cultural software development teams. Human Relations, 63, 1199-1221.

Bartelt, V.L. \& Dennis, A.R. (2014). Nature and nurture: The impact of automaticity and the structuration of communication on virtual team behavior and performance. MIS Quarterly, 38, 521-238.

Bechky, B.A. (2003). Sharing meaning across occupational communities: The transformation of understanding on a production floor. Organization Science, 14, 312-330.

Boland Jr, R.J., Lyytinen, K. \& Yoo, Y. (2007). Wakes of innovation in project networks: The case of digital 3-D representations in architecture, engineering, and construction. Organization Science, 18, 631647.

Brotheridge, C. M., Neufeld, D. J. \& Dyck, B. (2015). Communicating virtually in a global organization. Journal of Managerial Psychology, 53, 909-924.

Brown, J.S. \& Duguid, P. (2001). Knowledge and organization: A social-practice perspective. Organization Science, 12, 198-213.

Burton-Jones, A., McLean, E.R. \& Monod, E. (2014). Theoretical perspectives in IS research: From variance and process to conceptual latitude and conceptual fit. European Journal of Information Systems, 24, 664-679.

Callon, M. (2002). Writing and (re)writing devices as tools for managing complexity, In: Complexities Social Studies of Knowledge Practices,Law, L. \& Mol, A. (ed) Duke University Press, Durham, NC.

Carlile, P.R. (2002). A pragmatic view of knowledge and boundaries: Boundary objects in new product development. Organization Science, 13, 442-455.

Carlile, P.R. (2004). Transferring, translating and transforming: An integrative framework for managing knowledge across boundaries. Organization Science, 15, 555-568.

Choi, S. Y., Lee, H. \& Yoo, Y. (2010). The impact of information technology and transactive memory systems on knowledge sharing, application, and team performance: A field study. MIS Quarterly, 34, 855-870.

Cramton, C.D. (2001). The mutual knowledge problem and its consequences for dispersed collaboration. Organization Science, 12, 346-371.

Deng, X. N. \& Chi, L. (2015). Knowledge boundary spanning and productivity in information systems support community. Decision Support Systems, 80, 14-26.

Dougherty, D. (1992). Interpretive barriers to successful product innovation in large firms. Organization Science, 3, 179-202.

Eisenhardt, K.M. (1989). Building theories from case study research. Academy of Management Review, 14, 532-550.

Ekbia, H.R. (2009). Digital artifacts as quasi - objects: Qualification, mediation, and materiality. Journal 
of the American Society for Information Science and Technology, 60, 2554-2566.

Ellwart, T., Happ, C., Gurtner, A., \& Rack, O. (2015). Managing information overload in virtual teams: Effects of a structured online team adaptation on cognition and performance. European Journal of Work and Organizational Psychology, 24, 812-826.

Espinosa, J.A., Slaughter, S.A., Kraut, R.E. \& Herbsleb, J.D. (2007). Team knowledge and coordination in geographically distributed software development. Journal of Management Information Systems, 24, 135-169.

Evans, J. M., Hendron, M. G. \& Oldroyd, J. B. (2015). Withholding the Ace: The Individual- and UnitLevel Performance Effects of Self-Reported and Perceived Knowledge Hoarding. Organization Science, 26, 494-510.

Faulkner, P., \& Runde, J. (2019). Theorizing the Digital Object. MIS Quarterly, 43, 1279-1302.

Galbraight, J. (1973) Designing Complex Organizations. Addison-Wesley, Reading, MA.

Gilson, L.L., Maynard, M.T., Jones Young, N.C., Vartiainen, M. \& Hakonen, M. (2015). Virtual teams research: 10 years, 10 themes, and 10 opportunities. Journal of Management, 41, 1313-1337.

Golden, T.D. \& Raghuram, S. (2010). Teleworker knowledge sharing and the role of altered relational and technological interactions. Journal of Organizational Behavior, 31, 1061-1085.

Grant, R.M. (1996). Toward a knowledge - based theory of the firm. Strategic Management Journal, 17, 109-122.

Griffith, T.L., Sawyer, J.E. \& Neale, M.A. (2003). Virtualness and knowledge in teams: Managing the love triangle of organizations, individuals, and information technology. MIS Quarterly, 27, 265-287.

Havakhor, T., \& Sabherwal, R. (2018). Team processes in virtual knowledge teams: The effects of reputation signals and network density. Journal of Management Information Systems, 35, 266-318.

Hinds, P.J. \& Bailey, D.E. (2003). Out of sight, out of sync: Understanding conflict in distributed teams. Organization Science, 14, 615-632.

Hofstede, G., Hofstede, G. J. \& Minkov, M. (2005). Cultures and organizations: Software of the mind. New York: Mcgraw-hill.

Huvila, I., Anderson, T. D., Jansen, E. H., McKenzie, P., \& Worrall, A. (2017). Boundary objects in information science. Journal of the Association for Information Science and Technology, 68, 1807-1822.

Iyengar, K., Sweeney, J. R. \& Montealegre, R. (2015). Information technology use as a learning mechanism: the impact of IT use on knowledge transfer effectiveness, absorptive capacity, and franchisee performance. MIS Quarterly, 39, 615-642.

Jarzabkowski, P. \& Kaplan, S. (2015). Strategy tools-in-use: A framework for understanding "technologies of rationality" in practice. Strategic management journal, 36, 537-558.

Kallinikos, J., Aaltonen, A. \& Marton, A. (2013). The ambivalent ontology of digital artifacts. MIS Quarterly, 37, 357-370.

Kanawattanachai, P. \& Yoo, Y. (2007). The impact of knowledge coordination on virtual team performance over time. MIS Quarterly, 31, 783-808.

Kellogg, K.C., Orlikowski, W.J. \& Yates, J. (2006). Life in the trading zone: Structuring coordination across boundaries in postbureaucratic organizations. Organization Science, 17, 22-44.

Kilcullen, M., Feitosa, J., \& Salas, E. (2021). Insights from the Virtual Team Science: Rapid Deployment During COVID-19. Human Factors, published online. 
Klein, H.K. \& Myers, M.D. (1999). A set of principles for conducting and evaluating interpretive field studies in information systems. MIS Quarterly, 23, 67-93.

Kotlarsky, J., Scarbrough, H. \& Oshri, I. (2014). Coordinating Expertise Across Knowledge Boundaries in Offshore-Outsourcing Projects. MIS Quarterly, 38, 607-A5.

Kudaravalli, S., Faraj, S. \& Johnson, S. L. (2017). A Configural Approach to Coordinating Expertise in Software Development Teams. MIS Quarterly, 41, 43-64.

Lawrence, P.R. \& Lorsch, J.W. (1967). Organization and Environments. Harvard University Press, Boston, MA.

Lee, A.S. \& Baskerville, R.L. (2003). Generalizing generalizability in information systems research. Information Systems Research, 14, 221-243.

Leonardi, P.M. \& Bailey, D.E. (2008). Transformational technologies and the creation of new work practices: Making implicit knowledge explicit in task-based offshoring. MIS Quarterly, 32, 411-436.

Leonardi, P. M. \& Bailey, D. E. (2017). Recognizing and selling good ideas: Network articulation and the making of an offshore innovation hub. Academy of Management Discoveries, 3, 116-144.

Leonardi, P. M., Bailey, D. E., \& Pierce, C. S. (2019). The coevolution of objects and boundaries over time: Materiality, affordances, and boundary salience. Information Systems Research, 30, 665-686.

Levina, N. (2005). Collaborating on multiparty information systems development projects: A collective reflection-in-action view. Information Systems Research, 16, 109-130.

Levina, N. \& Vaast, E. (2005). The emergence of boundary spanning competence in practice: Implications for implementation and use of information systems. MIS Quarterly, 29, 335-363.

Magni, M., Ahujia, M. K. \& Maruping, L. M. (2018). Distant but Fair: Intra-Team Justice Climate and Performance in Dispersed Teams. Journal of Management Information Systems. 35, 1031-1059.

Malone, T.W. \& Crowston, K. (1994). The interdisciplinary study of coordination. ACM Computing Surveys, 26, 87-119.

Markus, M.L. \& Robey, D. (1988). Information technology and organizational change: causal structure in theory and research. Management Science, 34, 583-598.

Martins, L.L., Gilson, L.L. \& Maynard, M.T. (2004). Virtual teams: What do we know and where do we go from here? Journal of Management, 30, 805-835.

Mehta, N. \& Bharadwaj, A. (2015). Knowledge integration in outsourced software development: The role of sentry and guard processes. Journal of Management Information Systems, 32, 82-115.

Mesmer-Magnus, J.R., DeChurch, L.A., Jimenez-Rodriguez, M., Wildman, J. \& Shuffler, M. (2011). A meta-analytic investigation of virtuality and information sharing in teams. Organizational Behavior and Human Decision Processes, 115, 214-225.

Nonaka, I. (1994). A dynamic theory of organizational knowledge creation. Organization Science, 5, 1437.

Nonaka, I. \& Takeuchi, H. (1995). The Knowledge-creating Company: How Japanese Companies Create the Dynamics of Innovation. Oxford University Press, New York, NY.

Okhuysen, G.A. \& Bechky, B.A. (2009). Coordination in organizations: An integrative perspective. The Academy of Management Annals, 3, 463-502.

O'Leary, M.B. \& Cummings, J.N. (2007). The spatial, temporal, and configurational characteristics of geographic dispersion in teams. MIS Quarterly, 31, 433-452. 
O'Leary, M.B. \& Mortensen, M. (2010). Go (con)figure: Subgroups, imbalance, and isolates in geographically dispersed teams. Organization Science, 21, 115-131.

O'Leary, M.B., Wilson, J.M. \& Metiu, A. (2014). Beyond being there: The symbolic role of communication and identification in perceptions of proximity to geographically dispersed colleagues. MIS Quarterly, 38, 1219-1243.

Orlikowski, W.J. (2002). Knowing in practice: Enacting a collective capability in distributed organizing. Organization Science, 13, 249-273.

Peñarroja, V., Orengo, V., Zornoza, A. \& Hernández, A. (2013). The effects of virtuality level on taskrelated collaborative behaviors: The mediating role of team trust. Computers in Human Behavior, 29, 967-974.

Qureshi, I., Fang, Y., Haggerty, N., Compeau, D. R., \& Zhang, X. (2018). IT-mediated social interactions and knowledge sharing: Role of competence-based trust and background heterogeneity. Information Systems Journal, 28, 929-955.

Raghuram, S., Hill, S., Gibbs, J. \& Maruping, L. M. (2019). Virtual Work: Bridging Research Clusters. Academy of Management Annals, 13, 308-341.

Robert Jr, L.P., Dennis, A.R. \& Ahuja, M.K. (2008). Social capital and knowledge integration in digitally enabled teams. Information Systems Research, 19, 314-334.

Romanow, D., Arun, R. \& Keil, M. (2018). CPOE-Enabled Coordination: Appropriation for Deep Structure Use and Impacts on Patient Outcomes. MIS Quarterly, 42, 189-212.

Seidel, V.P. \& O'Mahony, S. (2014). Managing the repertoire: Stories, metaphors, prototypes, and concept coherence in product innovation. Organization Science, 25, 691-712.

Shannon, C.E. \& Weaver, W. (1949). The Mathematical Theory of Communication. University of Illinois press.

Slavova, M. \& Karanasios, S. (2018). When Institutional Logics Meet ICTs: Examining Hybrid Information Practices in Ghanaian Agriculture. Journal of the Association for Information Systems, 19, 775-812.

Star, S.L. (1989). The structure of ill-structured solutions: Heterogeneous problem-solving, boundary objects and distributed artificial intelligence, In: Readings in Distributed Artificial Intelligence, Huhns, M. \& Gasser, L. (ed Morgan Kaufman, Menlo Park, CA.

Strauss, A. \& Corbin, J. (1990). Basics of Qualitative Research. Sage, London.

Tim, Y., Pan, S. L., Ractham, P. \& Kaewkitipong, L. (2017). Digitally enabled disaster response: the emergence of social media as boundary objects in a flooding disaster. Information Systems Journal, 27, 197-232.

Tiwana, A. \& Mclean, E.R. (2005). Expertise integration and creativity in information systems development. Journal of Management Information Systems, 22, 13-43.

Tzabbar, D. \& Vestal, A. (2015). Bridging the social chasm in geographically distributed R\&D teams: The moderating effects of relational strength and status asymmetry on the novelty of team innovation. Organization Science, 26, 811-829.

Vaughan, R. (1992). Theory elaboration: The heuristics of case analysis. In H. Becker \& C. Ragin (Eds.), What is a case? New York: Cambrige University Press, 173-202.

Venkatesh, V., Brown, S. A. \& Bala, H. (2013). Bridging the Qualitiatve - Quantitative Divide: Guidelines for Conducting Mixed Methods Research in Information Systems. MIS Quarterly, 37, 21-54. 
Vlaar, P.W., van Fenema, P.C. \& Tiwari, V. (2008). Cocreating understanding and value in distributed work: How members of onsite and offshore vendor teams give, make, demand, and break sense. MIS Quarterly, 32, 227-255.

Waizenegger, L., McKenna, B., Cai, W., \& Bendz, T. (2020). An affordance perspective of team collaboration and enforced working from home during COVID-19. European Journal of Information Systems, 29, 429-442.

Walsham, G. (1993). Interpreting Information Systems in Organizations. Wiley, Chichester, UK.

Watson-Manheim, M.B. \& Bélanger, F. (2007). Communication media repertoires: Dealing with the multiplicity of media choices. MIS Quarterly, 31, 267-293.

Wenger, E. (1998). Communities of Practice: Learning, Meaning, and Identity. Cambridge University Press, Cambridge.

Yin, R.K. (2003). The Abridged Version of Case Study Research: Design and Method. Sage, London.

Zimmermann, A. \& Ravishankar, M.N. (2014). Knowledge transfer in IT offshoring relationships: The roles of social capital, efficacy and outcome expectations. Information Systems Journal, 24, 167-202.

Zuzul, T. W. (2019). "Matter Battles": Cognitive Representations, Boundary Objects, and the Failure of Collaboration in Two Smart Cities. Academy of Management Journal, 62, 739-764. 


\section{Appendix - Interview Protocol}

\section{Interview Introduction}

I am [the investigator's name] from [the university], currently doing my dissertation on knowledge management in virtual teams. Is this a good time for our interview?

[The organization] would like to understand how to help dispersed (or virtual) teams maximize their learning as they complete their team tasks and work as effectively as possible, because more firms like [the organization] are increasingly relying on such teams to accomplish critical knowledge-intensive work such as the work you are engaged in. I'd like to learn from your opinions, perspectives, and experience what it is that helps a virtual team to learn and collaborate well since I have been informed by [the sponsor] that you have experience in working with remote colleagues. I appreciate your time in responding to the following questions I have.

The following interview protocol is preliminary. It will have to be continually revised during data analysis to reflect the evolving concepts of interest.

\section{General Questions}

1. [GENERAL] I'd like to learn more about your job.

- Could you please tell me about your role in this organization? Your position, your key responsibilities, and job activities?

- Do you enjoy your job? What parts are most interesting? Most challenging?

- Are you in a team? If so, how do you collaborate in the team? What are the most interesting in the teamwork? Most challenging?

2. [GENERAL] I would like to understand the difference in work practice in your location and function relative to others in the organization.

- [LOCATION BOUNDARY] Do you interact with any team member you have never, or rarely, met? If so, what do you collaborate for? In which way do you collaborate? Why do you decide to collaborate this way? How do you like the communication with them in comparison to your colleague right here around you? Examples?

- [FUNCTION BOUNDARY] Do you interact/collaborate with any team member not in your functional area? If so, what do you collaborate for? How do you collaborate? Why do you decide to collaborate this way? How do you like the collaboration with them in comparison to colleagues of the same function? Examples?

3. [TEAM] I would like to learn how you feel about your current teamwork.

- Could you talk about your team? What does it do? What is the role of your team in the organization? How does your team work to achieve its goal?

- Do you see any difference among team members in terms of what people value, the way people think, and what they do to accomplish the team objective? Why do you think there is (not) such a difference? How do these differences affect your teamwork? What do you see the team doing to overcome/appreciate these differences? 
- In your opinion, are there any major challenges you are facing in terms of sharing knowledge and collaborating as a team? An example? How did you address these challenges? Why did you do so? What was the outcome? What do you think was the reason for the outcome?

4. [TEAM] I'd like to learn your view about the value you get out of working with your team.

- Do you think you and the team as a whole has been doing a great job? Why?

- Do you think the team as a whole is learning new things? How do you know? Why do you think so?

- Do you benefit from the teamwork in terms of personal learning? What do you learn? Why do you think these learning experiences are beneficial? How do you know you are learning? Examples?

- Can you think of three episodes where you find that you experienced learning through interaction with your remote and local team members? How did those happen?

5. [ICT USE] I would like to learn about your view and actual use of ICT.

- How do you interact with your peers in the team? How do you use them to do your job together with them? Do you use any tools? How do you find them useful? Why?

- Do you think your team members use these tools the same way you do? Why (not)?

- How about computer-based team collaboration tools (e.g., calendar, task management, discussion forums, reporting forms)? Do you find the way they are used in the team different from that of your local office or functional department? 


\section{Appendix - Example of Fieldwork Log}

\begin{tabular}{|c|c|c|c|c|c|c|}
\hline No. & Date & Hour & Activities & Theme & Outcome & Documents \\
\hline 1 & 17-Nov & 5 & $\begin{array}{l}\text { Site visit with } \\
\text { the contact } \\
\text { person }\end{array}$ & $\begin{array}{l}\text { Get familiar with } \\
\text { the teams }\end{array}$ & $\begin{array}{l}\text { An understanding of } \\
\text { the physical layout of } \\
\text { the site }\end{array}$ & Filed notes \\
\hline 2 & 21-Nov & 8 & Site observation & $\begin{array}{l}\text { Develop rapport } \\
\text { with the key team } \\
\text { members }\end{array}$ & $\begin{array}{l}\text { Trust and } \\
\text { understanding from } \\
\text { team members }\end{array}$ & $\begin{array}{l}\text { Access to the } \\
\text { Intranet and a } \\
\text { detailed look at } \\
\text { the PI site }\end{array}$ \\
\hline 3 & 22-Nov & 1 & $\begin{array}{l}\text { Conference call } \\
(20: 00-21: 00)\end{array}$ & $\begin{array}{l}\text { Project scheduling } \\
\text { across three } \\
\text { research sites }\end{array}$ & $\begin{array}{l}\text { An understanding of } \\
\text { projects chaired by } \\
\text { different personnel; } \\
\text { feedbacks, comments } \\
\text { and support. }\end{array}$ & $\begin{array}{l}\text { Access to project } \\
\text { management } \\
\text { files. }\end{array}$ \\
\hline 4 & 23-Nov & 0.5 & $\begin{array}{l}\text { Information } \\
\text { interview }\end{array}$ & $\begin{array}{l}\text { Challenges the } \\
\text { teams are facing in } \\
\text { coordination }\end{array}$ & $\begin{array}{l}\text { An understanding of } \\
\text { the challenges that the } \\
\text { teams were facing }\end{array}$ & $\begin{array}{l}\text { Interview } \\
\text { transcripts }\end{array}$ \\
\hline 5 & 24-Nov & 6.5 & $\begin{array}{l}\text { Site observation } \\
\text { on the PIT }\end{array}$ & $\begin{array}{l}\text { Look at the local } \\
\text { site }\end{array}$ & $\begin{array}{l}\text { An understanding of } \\
\text { daily practices in } \\
\text { knowledge sharing }\end{array}$ & Field notes \\
\hline 6 & 28-Nov & 8 & Site observation & $\begin{array}{l}\text { Observe everyday } \\
\text { practices and } \\
\text { activities of team } \\
\text { members }\end{array}$ & $\begin{array}{l}\text { An understanding of } \\
\text { the existence of } \\
\text { obstacles in } \\
\text { communication }\end{array}$ & Field notes \\
\hline 7 & 29-Nov & 1 & $\begin{array}{l}\text { Participation in } \\
\text { the audio- } \\
\text { meeting }\end{array}$ & $\begin{array}{l}\text { Align actions of } \\
\text { the three sites }\end{array}$ & $\begin{array}{l}\text { Observations of three- } \\
\text { site conference calls }\end{array}$ & Meeting memos \\
\hline 8 & 1-Dec & 1 & $\begin{array}{l}\text { Semi-structured } \\
\text { interview }\end{array}$ & $\begin{array}{l}\text { Personal } \\
\text { experience }\end{array}$ & $\begin{array}{l}\text { Insights about the } \\
\text { boundary spanner role }\end{array}$ & $\begin{array}{l}\text { Interview } \\
\text { transcript }\end{array}$ \\
\hline 9 & 5- Dec & 0.3 & $\begin{array}{l}\text { Semi-structured } \\
\text { interview }\end{array}$ & $\begin{array}{l}\text { Personal } \\
\text { experience }\end{array}$ & $\begin{array}{l}\text { An understanding of } \\
\text { communication within } \\
\text { and across different } \\
\text { sites }\end{array}$ & $\begin{array}{l}\text { Interview } \\
\text { transcript }\end{array}$ \\
\hline 10 & 25-Dec & 1 & $\begin{array}{l}\text { Semi-structured } \\
\text { interview }\end{array}$ & $\begin{array}{l}\text { Personal } \\
\text { experience }\end{array}$ & $\begin{array}{l}\text { Insights about the } \\
\text { challenges dealing with } \\
\text { remote peers }\end{array}$ & $\begin{array}{l}\text { Interview } \\
\text { transcript }\end{array}$ \\
\hline
\end{tabular}

